\title{
Facile Synthesis and Characterization of Symmetric $N$-[(Phenylcarbonyl) carbamothioyl]benzamide Thiourea: Experimental and Theoretical Investigations
}

\author{
Rafael G. Silveira, ${ }^{a, b}$ Anderson J. L. Catão, ${ }^{a}$ Beatriz N. Cunha, ${ }^{a, b}$ Fernando Almeida, ${ }^{c}$ \\ Rodrigo S. Correa, ${ }^{d}$ Luan F. Diniz, ${ }^{e}$ Juan C. Tenório, ${ }^{e}$ Javier Ellena, ${ }^{e}$ \\ Aleksey E. Kuznetsov, ${ }^{f}$ Alzir A. Batista*,a and Edésio Alcântara ${ }^{g}$
}

${ }^{a}$ Departamento de Química, Universidade Federal de São Carlos, 13565-905 São Carlos-SP, Brazil

${ }^{b}$ Instituto Federal Goiano, Campus Ceres, 76300-000 Ceres-GO, Brazil

'Instituto de Ciências Biomédicas, Universidade de São Paulo, 05508-900 São Paulo-SP, Brazil

${ }^{d}$ Departamento de Química, Instituto de Ciências Exatas e Biológicas,

Universidade Federal de Ouro Preto, 35400-000 Ouro Preto-MG, Brazil

eInstituto de Física de São Carlos, Universidade de São Paulo, 13560-970 São Carlos-SP, Brazil

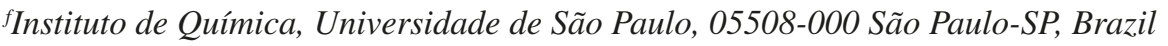

${ }^{8}$ Instituto de Química, Universidade Federal de Goiás, 74001-970 Goiânia-GO, Brazil

\begin{abstract}
A thiourea derivative, $\mathrm{N}$-[(phenylcarbonyl)carbamothioyl]benzamide, was synthesized and characterized by elemental analysis, thermal analysis, spectroscopic methods (Fourier transform infrared (FTIR), UV-Vis, Raman, matrix-assisted laser desorption-ionization time-of-flight mass spectrometry (MALDI-TOF), tandem mass spectrometry (MS/MS) and nuclear magnetic resonance (NMR)) and quantum-chemical calculations. The synthetic route was simple and efficient, conducted just by one-step and no purification step was needed. The compound crystallizes in a non-centrosymmetric orthorhombic crystal system with a $\mathrm{P} 22_{1} 2_{1} 2_{1}$ space group, with $a=5.06220(10) \AA, b=11.8623(3) \AA, c=21.9682(8) \AA$. The molecular conformation of the solid is stabilized by the $\mathrm{N}-\mathrm{H} \cdots \mathrm{O}$ intramolecular hydrogen bond, which was present in the $\mathrm{X}$-ray structure and was also found in the optimized geometry. The theoretical analysis showed that this strong interaction remains even when molecules are solvated, i.e., the rotation barrier and the hydrogen bond strength are greater than the solvent stabilization energy. In addition to this hydrogen bond effect, the relative position of phenyl groups has a certain influence on the chemical behavior of this thiourea and probably for other phenylthioureas.
\end{abstract}

Keywords: thioureas derivative, synthesis, intramolecular hydrogen bond

\section{Introduction}

Thioureas are a well-known class of organic compounds, which have been studied for several decades. ${ }^{1,2}$ These compounds have proved to be very attractive from the synthetic point of view. Therefore, it is possible to use thioureas for designing numerous compounds with chemical groups of biological interest, thus producing almost a limitless variety of structures with new physicochemical characteristics. This makes great contributions to the knowledge of these compounds. ${ }^{3-5}$ Thioureas are

*e-mail: daab@ufscar.br among the most reactive compounds containing sulfur atoms in the functional groups. Their reactivity has been broadly reported to be used in catalysis for asymmetric synthesis with high selectivity and yield, and several studies have reported the coordination of thioureas with metal centers, making them attractive to be used in the recovery of precious metals. ${ }^{6,7}$

Molecules containing the thiocarbonyl group are versatile synthetic intermediates and numerous synthetic applications have been developed, which serve as basic building blocks for the synthesis of heterocyclic compounds, natural products, guanidines, aryl isothiocyanate, acrylamide, and benzothiazole. ${ }^{8} 9$ Furthermore, their 
properties have been explored from the biological point of view: they are used as anticancer, antioxidant, anti-HIV, anti-parasitic, anti-inflammatory, fungicide, herbicide, antiviral, rodenticidal and plant growth regulator agents. ${ }^{10-13}$

Currently reported synthetic methodologies are still based on classic approaches, despite the numerous studies of thioureas and derivatives available so far. ${ }^{3,4,6,10}$ These methodologies entail using reactants such as fluorescein isothiocyanate, thiophosgene and thiocyanate salts, which are highly toxic and harmful to the environment. Thus, the search for new synthetic routes that provide the minimization of the number of reaction steps and use less toxic reactants, polluting the environment less, poses as a considerable and promising challenge. Stimulated by this challenge, here we report on a synthetic route for a new symmetric thiourea derivative, $N$-[(phenylcarbonyl) carbamothioyl]benzamide (BT), which is simple and fast, producing a compound with high purity and high yield, using just recrystallization as the purification technique. We also present a complete characterization of the BT compound by infrared (IR), UV-Vis, Raman, $\mathrm{X}$-ray diffraction, nuclear magnetic resonance (NMR) $\left({ }^{1} \mathrm{H},{ }^{13} \mathrm{C}\left\{{ }^{1} \mathrm{H}\right\}\right.$, distortionless enhancement by polarization transfer (DEPT)-135, correlation spectroscopy (COSY), heteronuclear single quantum correlation (HSQC)), supported by detailed theoretical calculations.

\section{Experimental}

Material and methods

\section{Procedure for synthesis of BT compound}

All chemicals used were of analytical grade. The benzoyl chloride and the thiourea were purchased from Sigma-Aldrich ${ }^{\circledast}$ and used without further purification. Thiourea $(6.5 \mathrm{~g}, 0.085 \mathrm{~mol})$ was stirred in acetone $(20 \mathrm{~mL})$ in an ice bath and benzoyl chloride $(21 \mathrm{~mL}, 0.18 \mathrm{~mol})$ was slowly added dropwise. The reaction was continued for $45 \mathrm{~min}$ and then the reaction mixture was transferred to a rotatory evaporator until the solvent completely evaporated, yielding a white solid. This product was further dissolved in $20 \mathrm{~mL}$ of dichloromethane and $20 \mathrm{~mL}$ of $10 \%$ aqueous solution of $\mathrm{NaHCO}_{3}$. The organic phase (dichloromethane) was separated, $\mathrm{MgSO}_{4}$ was added and then filtered. The filtrate was reduced to about $5 \mathrm{~mL}$, added to $1 \mathrm{~mL}$ of hexane and left in the refrigerator overnight. The crystals formed were filtered without any purification by column chromatography.

Yield: 93\%, yellow solid. Elementary analysis, calcd. (exp.): C, 63.36(63.45)\%; H, 4.25(3.96)\%; $\mathrm{N}, 9.85(10.12) \%$. UV-Vis, spectrum in dichloromethane,
$260 \mathrm{~nm}\left(\varepsilon=21732.3 \mathrm{~mol}^{-1} \mathrm{~L} \mathrm{~cm}^{-1}\right), 308 \mathrm{~nm}$ $\left(\varepsilon=11189.8 \mathrm{~mol}^{-1} \mathrm{~L} \mathrm{~cm}^{-1}\right)$ and dimethyl sulfoxide (DMSO) $264 \mathrm{~nm}\left(\varepsilon=19564.2 \mathrm{~mol}^{-1} \mathrm{~L} \mathrm{~cm}^{-1}\right), 312 \mathrm{~nm}$ $\left(\varepsilon=9968.3 \mathrm{~mol}^{-1} \mathrm{~L} \mathrm{~cm}^{-1}\right) ; \mathrm{m} / z$ 285.07; IR $(\mathrm{KBr}) v / \mathrm{cm}^{-1}$ $v(\mathrm{NH}) 3361, v\left(\mathrm{C}-\mathrm{H}_{\mathrm{ar}}\right) 3057, v(\mathrm{C}=\mathrm{O}) 1635, v(\mathrm{C}-\mathrm{N}) 1300$, $v(\mathrm{C}=\mathrm{S}) 1227 ;{ }^{1} \mathrm{H}$ NMR $\left(400.21 \mathrm{MHz}, \mathrm{CD}_{2} \mathrm{Cl}_{2}\right) \delta 7.72$ (m, 2H), $7.61(\mathrm{~m}, 4 \mathrm{H}), 8.03(\mathrm{~m}, 4 \mathrm{H}) ;{ }^{13} \mathrm{C}\left\{{ }^{1} \mathrm{H}\right\}$ NMR (400.21 MHz, $\left.\mathrm{CD}_{2} \mathrm{Cl}_{2}\right) \delta 128.15(\mathrm{C} 2, \mathrm{C} 9), 129.6(\mathrm{C} 3$, C10), 134.16 (C4, C11), 132.61 (C1, C8), 166.9(C6), 177.8 (C5, C7).

\section{Thermal analysis}

Differential scanning calorimetry (DSC) measurements were performed using a Shimadzu DSC-60 instrument. The sample $(2.5 \pm 0.5 \mathrm{mg})$ was placed in an open aluminum pan and heated under $\mathrm{N}_{2}$ flow $\left(50 \mathrm{~mL} \mathrm{~min}^{-1}\right)$ from 25 to $500{ }^{\circ} \mathrm{C}$ at a heating rate of $10{ }^{\circ} \mathrm{C} \mathrm{min}{ }^{-1}$. Thermogravimetric (TGA) analysis was carried out with a Shimadzu TGA-60 thermobalance. Approximately $5.0 \mathrm{mg}$ of the sample was placed in an aluminum pan and heated at $10{ }^{\circ} \mathrm{C} \mathrm{min}^{-1}$ under a $\mathrm{N}_{2}$ atmosphere $\left(50 \mathrm{~mL} \mathrm{~min}^{-1}\right)$ from 25 to $500{ }^{\circ} \mathrm{C}$. The resulting data were analyzed using the Shimadzu TA-60 software (version 2.2).

Hot-stage polarized optical microscopy (HSM) was performed using a Leica DM2500P microscope connected to Linkam T95-PE hot-stage equipment under air atmosphere. Data were visualized using Linksys 32 software for the hot-stage control. The single crystal of the BT compound was placed in a $13 \mathrm{~mm}$ glass coverslip within a $22 \mathrm{~mm}$ diameter silver heating block inside the stage. The sample was heated at a ramp rate of $10{ }^{\circ} \mathrm{C} \mathrm{min}-1$ over a temperature range from $30^{\circ} \mathrm{C}$ until the crystal has melted.

\section{X-ray crystallography}

Single crystals of BT were selected and the molecular structures were resolved at $293 \mathrm{~K}$ using graphite monochromated Mo $K_{\alpha}$ radiation $(\lambda=0.71073 \AA$ ). Data were acquired on a Bruker APEX II CCD diffractometer and the structures were resolved by direct methods using SHELXS. ${ }^{14}$ Non-hydrogen atom positions were determined by Fourier-difference map analyses with refinements carried out with the SHELXL package using full-matrix least squares on $F^{2}$ with anisotropic displacement parameters. ${ }^{15}$ All $\mathrm{H}$-atoms were stereochemically positioned and refined with the riding model. ${ }^{16}$ Table 1 summarizes the selected crystallography data.

\section{Spectroscopies}

Solvents used for spectroscopic studies were of the spectroscopic grade. The IR spectrum was recorded using an FTIR Bomem-Michelson 102 spectrometer in 
Table 1. Crystal and structure refinement data for the BT compound

\begin{tabular}{|c|c|}
\hline Empirical formula & $\mathrm{C}_{15} \mathrm{H}_{12} \mathrm{~N}_{2} \mathrm{O}_{2} \mathrm{~S}$ \\
\hline Formula weight & 284.33 \\
\hline Temperature / K & $293(2)$ \\
\hline Wavelength / $\AA$ & 0.71073 \\
\hline Crystal system & orthorhombic \\
\hline Space group & $\mathrm{P} 2_{1} 2_{1} 2_{1}$ \\
\hline \multirow[t]{3}{*}{ Unit cell dimensions } & $a=5.0620(10) \AA ; \alpha=90^{\circ}$ \\
\hline & $b=11.8620(3) \AA ; \beta=90^{\circ}$ \\
\hline & $c=21.9680(8) \AA ; \gamma=90^{\circ}$ \\
\hline Volume / $\AA^{3}$ & $1319.08(6)$ \\
\hline $\mathrm{Z}$ & 4 \\
\hline Density (calculated) / (mg m $\left.{ }^{-3}\right)$ & 1.432 \\
\hline Absorption coefficient / $\mathrm{mm}^{-1}$ & 0.248 \\
\hline $\mathrm{F}(000)$ & 592 \\
\hline Theta range for data collection / degree & 3.269 to 26.255 \\
\hline Reflections collected & 1576 \\
\hline Independent reflections & $1576[\mathrm{R}(\mathrm{int})=0.055]$ \\
\hline Completeness to theta $=25.242^{\circ} / \%$ & 99.8 \\
\hline Refinement method & full-matrix least-squares on $F^{2}$ \\
\hline Data / restraints / parameters & $1576 / 0 / 182$ \\
\hline Goodness-of-fit on $F^{2}$ & 1.093 \\
\hline Final $\mathrm{R}$ indices $[\mathrm{I}>2 \operatorname{sigma}(\mathrm{I})]$ & $\mathrm{R}_{1}=0.0550, \mathrm{wR}_{2}=0.1376$ \\
\hline $\mathrm{R}$ indices (all data) & $\mathrm{R}_{1}=0.0731, \mathrm{wR}_{2}=0.1584$ \\
\hline Absolute structure parameter & $0.16(19)$ \\
\hline Extinction coefficient & $0.027(7)$ \\
\hline Largest diff. peak and hole / e. $\AA^{-3}$ & 0.534 and -0.342 \\
\hline
\end{tabular}

the $4000-400 \mathrm{~cm}^{-1}$ region using solid samples pressed into $\mathrm{KBr}$ pellets. Raman spectra were obtained using a Bruker FT-Raman spectrophotometer in the $4000-400 \mathrm{~cm}^{-1}$ region, model RFS/100/S, using a Nd:YAG laser with power of $60 \mathrm{~mW}$ and wavelength of $1064 \mathrm{~nm}$. UV-Vis spectra were recorded using an HP8452A (diode array) spectrophotometer. Solution with the concentration of $4.4 \times 10^{-5} \mathrm{~mol} \mathrm{~L}^{-1}$ in dimethyl sulfoxide (DMSO) and quartz cells of $1.0 \mathrm{~cm}$ path length were used in the analysis. The ${ }^{1} \mathrm{H},{ }^{13} \mathrm{C}$, DEPT-135 and advanced 2D NMR techniques such as gradient enhanced, ${ }^{1} \mathrm{H}-{ }^{1} \mathrm{H}$ COSY, ${ }^{1} \mathrm{H}-{ }^{13} \mathrm{C}$ HSQC correlation were used. These analyses were performed in $\mathrm{CD}_{2} \mathrm{Cl}_{2}$ as a solvent in a $5 \mathrm{~mm}$ sample tube at $293 \mathrm{~K}$ using a Bruker Avance III DRX 400 spectrometer working at 400 and $100 \mathrm{MHz}$ at $9.4 \mathrm{~T}$, for ${ }^{1} \mathrm{H}$ and ${ }^{13} \mathrm{C}$, respectively.

\section{Mass spectrometry}

The samples were analyzed with a matrix-assisted laser desorption-ionization time-of-flight (MALDI-TOF)
Autoflex speed smart-beam mass-spectrometer (Bruker Daltonics) using FlexControl software (version 3.3, Bruker Daltonics). Spectra were recorded in the positive reflector mode (laser frequency, $500 \mathrm{~Hz}$; extraction delay time, $130 \mathrm{~ns}$; ion source 1 voltage, $19.0 \mathrm{kV}$; ion source 2 voltage, $16.8 \mathrm{kV}$; lens voltage, $7.9 \mathrm{kV}$; reflector 1 , $21.0 \mathrm{kV}$; reflector $2,9.35 \mathrm{kV}$; mass range, 100 to $1000 \mathrm{Da}$ ). For each spectrum, 5000 shots, in 500-shot steps, were summed from different positions of the target, collected and analyzed. All spectra were calibrated by using adrenaline $[\mathrm{M}+\mathrm{H}]^{+}=184.09682$, caffeine $[\mathrm{M}+\mathrm{H}]^{+}=195.08765$, lisinopril $[\mathrm{M}+\mathrm{H}]^{+}=406.23365$ and reserpine $[\mathrm{M}+\mathrm{H}]^{+}=609.28066$.

For tandem mass spectrometry (MS/MS) experiments, the instrument was set to LIFT mode (laser frequency, $200 \mathrm{~Hz}$; extraction delay time, $120 \mathrm{~ns}$; ion source 1 voltage, $6.0 \mathrm{kV}$; ion source 2 voltage, $5.3 \mathrm{kV}$; lens voltage, $3.0 \mathrm{kV}$; reflector $1,27.0 \mathrm{kV}$; reflector $2,11.6 \mathrm{kV}$; lift $1,19.0 \mathrm{kV}$; lift 2, $4.40 \mathrm{kV}$ ), and 2000 shots were summed in 500-shot steps for each acquired spectrum.

A sample of $10 \mu \mathrm{g} \mathrm{mL}^{-1}$ of the BT solution was prepared in $\mathrm{CH}_{3} \mathrm{OH} / \mathrm{H}_{2} \mathrm{O}(50: 50$, v/v) with $1 \%$ of trifluoroacetic acid (TFA) and $1 \mu \mathrm{L}$ was applied to a NALDI ${ }^{\circledR}$ target (nanostructured laser desorption ionization targets, Nanosys, Inc.), which does not require any kind of matrix for the ionization of the analyte.

\section{Computational details}

All calculations were performed using the Gaussian 09 package. ${ }^{17}$ The study was done using the $6-311++\mathrm{G}(2 \mathrm{~d}, 2 \mathrm{p})$ basis set. ${ }^{18-20}$ It was performed geometry optimizations and frequency calculations using the B3LYP density functional. ${ }^{21,22}$ B3PW91 and M062X functionals were also used for comparison purposes. ${ }^{21-24} \mathrm{UV}$-Vis spectra were computed using CAM-B3LYP functional, which takes dispersion corrections into account. ${ }^{25}$ The BT molecule was studied in the gas phase and with implicit solvent effects in both acetone and DMSO. These two solvents were employed as characteristic representatives of protic and aprotic solvents (dielectric constants $\varepsilon=20.7$ and 46.7, respectively). Considering the implicit solvent effects, the vibrational geometries and frequencies were calculated using the self-consistent reaction field IEF-PCM (integral equation formalism- polarizable continuum model) method (the UFF default model used in the Gaussian 09 package, with the electrostatic scaling factor $\alpha$ set to 1.0$){ }^{26-28} \mathrm{We}$ also performed a relaxed scan around the $\mathrm{H} 1-\mathrm{N} 1 \cdots \mathrm{N} 2-\mathrm{H} 2$ dihedral angle at the same level of theory. The scan was done in steps of $20^{\circ}$ to complete $360^{\circ}$. The characteristics of the $\mathrm{O} \cdots \mathrm{H}-\mathrm{N}$ hydrogen bond was theoretically explored and analyzed via natural bond orbital (NBO) and quantum 
theory of atom in molecules (QTAIM). ${ }^{29,30}$ Electron density distribution function $\rho(\mathrm{r})$, electron localization function (ELF) and the Laplacian of $\rho(r)$ were calculated from wave function data (B3LYP/6-311++G(2d,2p)) of the equilibrium geometry for the cis- and trans-conformers of BT. All the wave function analysis were performed using Multiwfn 3.6 software package..$^{31,32}$

\section{Results and Discussion}

\section{Synthesis of the BT compound}

The one-step synthesis of thioamide $N$-[(phenylcarbonyl) carbamothioyl] benzamide (BT) is outlined in Figure 1.

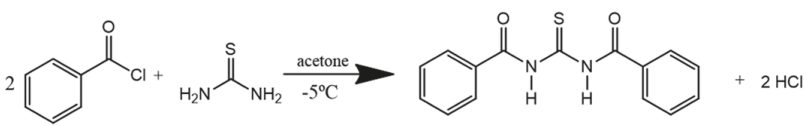

Figure 1. Synthetic route of BT.

The solid-state structure of the BT was established by $\mathrm{X}$-ray crystallography and the NMR data obtained from a $\mathrm{CD}_{2} \mathrm{Cl}_{2}$ solution are consistent with the X-ray structure. The synthetic methodology used here is easier and faster than the traditional methodologies used for synthesis of thioureas and/or benzamides. ${ }^{33-35}$ In general, the traditional process is as follows: the reaction between the respective organic chloride (benzyl, acyl chloride, etc.) and KSCN followed by the addition of the amine with the functional group of interest. After this step, generally a further purification step is required per chromatographic column.

Our synthesis uses less amount of solvent and is performed in a fewer number of reaction steps (atom economy), i.e., without a purification step, generating fewer residues to be treated. The reaction yield was $93 \%$. High purity was also achieved as shown in the characterization sections. The final product is presented in the form of needle-shaped yellow crystals and no purification by column chromatography was required. The product, which melting point is $175{ }^{\circ} \mathrm{C}$, is soluble in acetone, dichloromethane, DMSO, ethyl ether and insoluble in water.

\section{Thermal characterization}

The thermal profile was assessed by a combination of DSC, TGA and HSM techniques. TGA and DSC curves of the BT compound are shown in Figures $2 a$ and $2 b$, respectively.

The structure was found to be stable between 30 and ca. $170{ }^{\circ} \mathrm{C}$. The DSC curve exhibits an endothermic

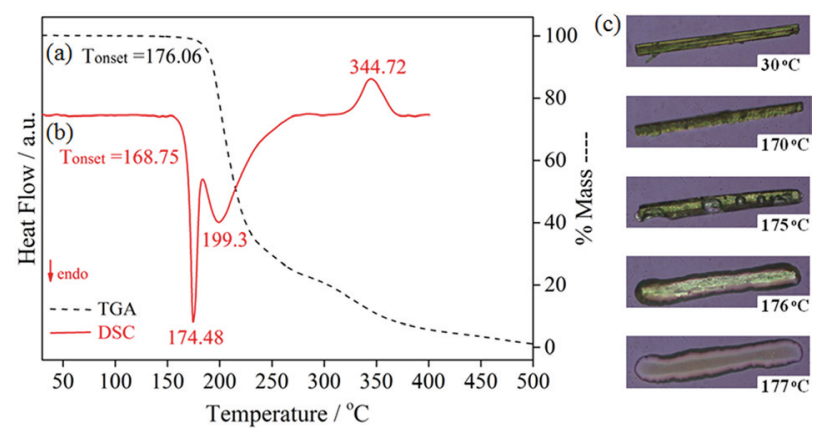

Figure 2. (a) TGA; (b) DSC curves and (c) HSM images of BT.

peak characteristic of a melting process at $174.48{ }^{\circ} \mathrm{C}$ $\left(\mathrm{T}_{\text {onset }}=168.75^{\circ} \mathrm{C}\right)$. This event is followed by another endothermic peak at $199.3{ }^{\circ} \mathrm{C}$, attributed to the first stage of thermal decomposition. These events are in agreement with the TGA curve, which shows that the BT compound is thermally stable up to $176{ }^{\circ} \mathrm{C}$ before it starts to lose mass. The thermal decomposition also appears in the DSC curve as an exothermic peak at $344.72{ }^{\circ} \mathrm{C}$ and, as expected, a gradual weight loss is observed in the TGA curve at this temperature. Although HSM and DSC/TGA experiments were performed under different atmospheres, the interpretation of DSC/TGA results was successfully confirmed by the HSM experiments. The HSM images (Figure 2c) show that a single crystal of the compound BT starts to melt at around $170{ }^{\circ} \mathrm{C}$ and, above $177^{\circ} \mathrm{C}$, it is completely melted into a liquid droplet. No other thermal event was observed before the melting.

In summary, thermal analysis shows the absence of solvent molecules in the crystalline structure and reveals that the compound decomposes in two steps over the temperature range of $176-263{ }^{\circ} \mathrm{C}$. The first decomposition step is the most important stage and occurs with a mass loss of $74.6 \%$, consistent with the evolution of the two benzoyl moieties and remaining thiourea group (loss of weight calculated, 73.9\%). The second step is compatible with a mass loss of $15.61 \%$ and might be attributed to decomposition of the thiourea group.

\section{X-ray crystallography}

The molecular structure of the compound was confirmed by X-ray crystallography (Figure 3 ). The BT crystals were obtained in the form of yellow needles. One well-shaped prismatic crystal with dimensions of $0.069 \times 0.207 \times 0.319 \mathrm{~mm}$ was used to collect X-ray data. The results show that the compound crystallizes in a non-centrosymmetric orthorhombic space group $\mathrm{P} 2{ }_{1} 2_{1} 2_{1}$ with just one molecule per asymmetric unit. The molecule possesses a quasi-planar configuration with the carbonyl 
groups in different orientations with respect to the sulfur atom, where one is cis-oriented and the other one is transoriented. In the literature, these two different conformations are denoted as $\mathrm{S}$ and $\mathrm{U}$ (the letter reflects the position of the $\mathrm{C}=\mathrm{O}$ and $\mathrm{C}=\mathrm{S}$ double bonds) relative to the $\mathrm{N}-\mathrm{H}$ bond. As can be seen, the S1-C1-N1-C2-O1 moiety adopts a U conformation, while the $\mathrm{S} 1-\mathrm{C} 1-\mathrm{N} 2-\mathrm{C} 9-\mathrm{O} 2$ moiety occurs in $\mathrm{S}$ conformation. This last conformation is stabilized by an intramolecular $\mathrm{N} 1-\mathrm{H} 1 \cdots \mathrm{O} 2$ hydrogen bond, an interaction often reported in the literature on benzoylthioureas type compounds..$^{36-38}$

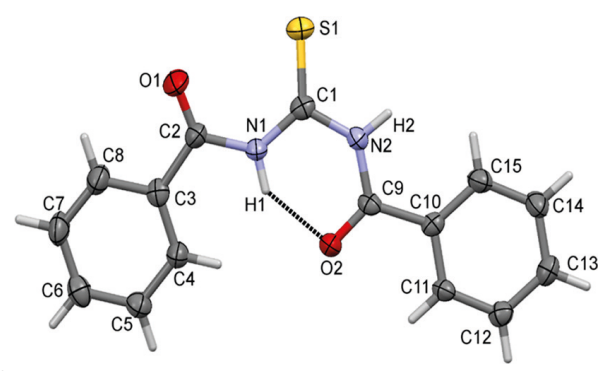

Figure 3. Crystal structure of the BT compound, with selected atoms labeled and ellipsoids at $30 \%$ of probability.

The geometric parameter analyses of the compound were carried out using Mogul, a valuable knowledge base for analyzing the conformational and geometric features of a molecule under study. ${ }^{39}$ Using the structure (BT) as a base, it is possible to search for similar compounds or substructures of thioureas deposited in the Cambridge Crystallographic Data Centre (CCDC). Using the Mogul program, as expected, all bond lengths and bond angle values agree statistically with those found for similar compounds. Table 1 shows the parameters for refinement and Table 2 presents selected fragment (theoretical and experimental) values with the mean values expected from the Mogul program.

The angles $\mathrm{S} 1-\mathrm{C} 1-\mathrm{N} 1\left(127.62^{\circ}\right)$ and $\mathrm{S} 1-\mathrm{C} 1-\mathrm{N} 2$ $\left(119.26^{\circ}\right)$ indicate the presence of $\mathrm{sp}^{2}$ carbon of thione. The same trend is also observed for the angles involving the carbon atoms of amide groups. The bond distances N2-C1 and N2-C9 have values of 1.402(5) and 1.379(5) A, respectively, which are in good agreement with those expected for amide derivatives. ${ }^{40}$ The bond length $\mathrm{C} 1=\mathrm{S} 1$ [1.634(4) $\AA$ ] is consistent with $\mathrm{C}=\mathrm{S}$ double bonds of thiones. Furthermore, bond lengths $\mathrm{C} 2-\mathrm{O} 1[1.205 \AA]$ and $\mathrm{C} 9=\mathrm{O} 2[1.231 \AA]$ show values characteristic of the carbonyl groups of amides. As can be seen, the $\mathrm{C} 2-\mathrm{O} 1$ bond is slightly longer than the $\mathrm{C} 9=\mathrm{O} 2$ bond, indicating a pure double bond character in the $\mathrm{C} 9=\mathrm{O} 2$ fragment. As can be seen, the $\mathrm{C} 2-\mathrm{O} 1$ group is involved in a resonance-assisted hydrogen bond (RAHB), with the O2-C9-N2-C1-N1-H1 forming a stable six-membered ring. The well-oriented

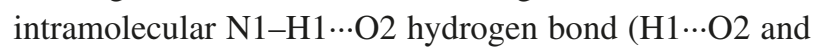

Table 2. Bond distances for the BT compound: theoretical and experimental values obtained by $\mathrm{X}$-ray diffraction and mean values from Mogul program data for some selected fragments

\begin{tabular}{lccc}
\hline Fragment & $\begin{array}{c}\text { Theoretical } \\
\text { value / }\end{array}$ & $\begin{array}{c}\text { Experimental } \\
\text { value / }\end{array}$ & $\begin{array}{c}\text { Mean values } \\
\text { from Mogul } \\
\text { analysis / }\end{array}$ \\
\hline C1-N1 & 1.368 & 1.363 & $1.388(17)$ \\
C1-N2 & 1.411 & 1.402 & $1.388(17)$ \\
C1-S1 & 1.688 & 1.632 & $1.675(25)$ \\
C9-N2 & 1.384 & 1.379 & $1.374(18)$ \\
O1-C2 & 1.238 & 1.205 & $1.228(21)$ \\
O2-C9 & 1.261 & 1.231 & $1.228(21)$ \\
C2-N1 & 1.409 & 1.397 & $1.374(18)$ \\
C3-C2 & 1.495 & 1.506 & $1.497(21)$ \\
C4-C3 & 1.406 & 1.374 & $1.389(16)$ \\
C5-C4 & 1.396 & 1.398 & $1.384(18)$ \\
C6-C5 & 1.397 & 1.381 & $1.377(23)$ \\
C6-C7 & 1.399 & 1.376 & $1.377(23)$ \\
C7-C8 & 1.391 & 1.388 & $1.384(18)$ \\
C8-C3 & 1.405 & 1.389 & $1.389(16)$ \\
C10-C9 & 1.485 & 1.495 & $1.497(21)$ \\
C11-C10 & 1.404 & 1.387 & $1.389(16)$ \\
C12-C11 & 1.393 & 1.386 & $1.384(18)$ \\
C13-C12 & 1.398 & 1.390 & $1.377(23)$ \\
C13-C14 & 1.398 & 1.391 & $1.377(23)$ \\
C14-C15 & 1.392 & 1.385 & $1.384(18)$ \\
C15-C10 & 1.405 & 1.397 & $1.389(16)$ \\
\hline
\end{tabular}

$\mathrm{N} 1 \cdots \mathrm{O} 1$ distances of 1.864 and $2.592 \AA$, respectively) contributes mainly to stabilization of the molecular conformation.

In the BT structure, intermolecular forces are very important for crystal packing stabilization. The $\mathrm{C} 2=\mathrm{O} 1$ carbonyl group acts as an acceptor of the $\mathrm{H} 2$ atom of N2-H2 amine group to form a classical hydrogen bond, which gives rise to an infinite one-dimensional ribbon along the $b$ axis (Figure 4). By analyzing the crystal packing, we can see that the existence of $\mathrm{C} 15-\mathrm{H} 15 \cdots \mathrm{O} 1$ weak interaction is largely influenced by the strong $\mathrm{N} 2-\mathrm{H} 2 \cdots \mathrm{O} 1$ hydrogen bond, forming a well orientated $\mathrm{H} 15 \cdots \mathrm{O} 1$ contact with the distance of $2.324 \AA$. In addition, the $\mathrm{C} 8-\mathrm{H} 8 \cdots \mathrm{S} 1$ $(2.748 \AA$ ) weak intermolecular hydrogen bond is observed. The contributions of all intermolecular contacts have been studied in detail using the Hirshfeld surfaces (HS).

\section{Hirshfeld surface analysis}

In recent years, we have explored intermolecular contacts of thiourea derivatives using the Hirshfeld surfaces 


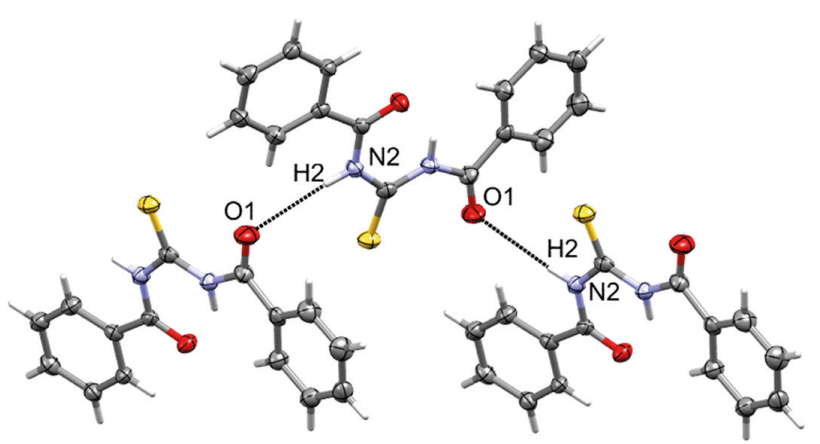

Figure 4. Classical intermolecular hydrogen bonds stabilizing the crystal packing along the [010] direction.

(HS) and fingerprints plots. In this study, the results of this analysis are represented in Figure 5.

The Hirshfeld surface of the compound, representing the $3 \mathrm{D} \mathrm{d}_{\text {norm }}$, illustrates regions which are more suitable to be involved in intermolecular contacts. As depicted by the HS, in the region of the surface shown in red, the distances between internal and external atoms are shorter

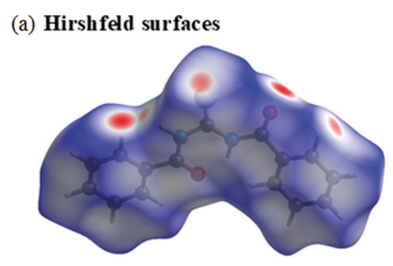

(compound)
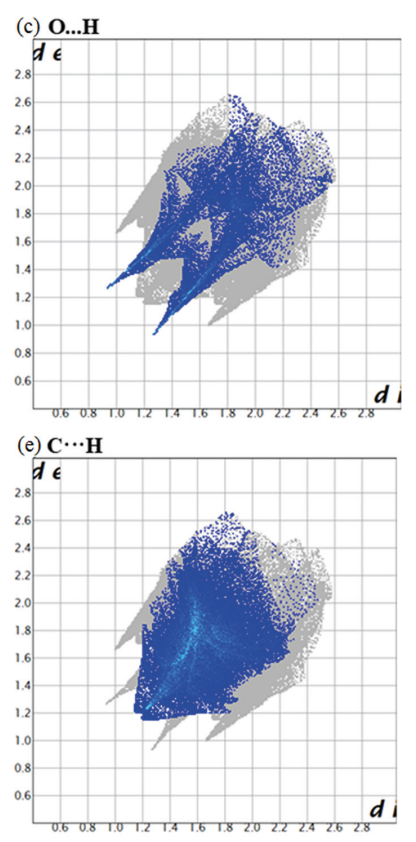

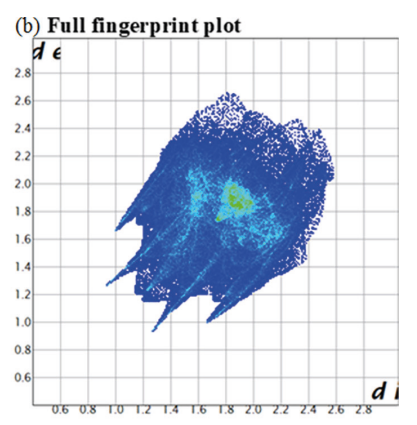

(d) $\mathbf{S} \cdots \mathbf{H}$
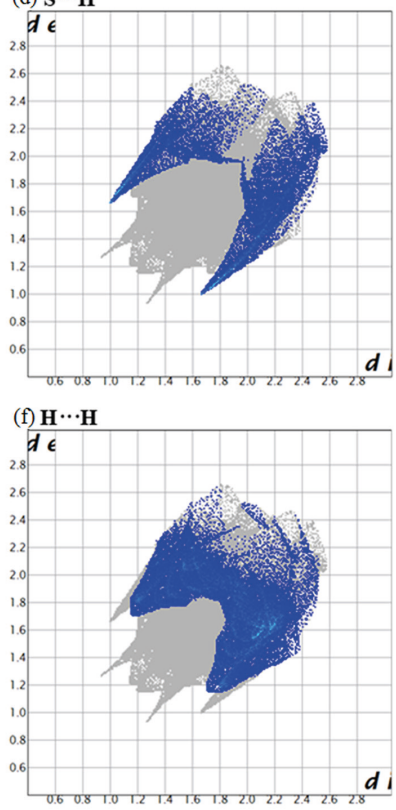

Figure 5. (a) Hirshfeld surface and (b-f) fingerprint plots for the BT compound. The full fingerprint is shown in (b), and graphs (c), (d) and (e) illustrate the $\mathrm{O} \cdots \mathrm{H}, \mathrm{S} \cdots \mathrm{H}$ and $\mathrm{C} \cdots \mathrm{H}$, (f) $\mathrm{H} \cdots \mathrm{H}$ intermolecular contacts, respectively. than the sum of van der Waals (vdW) radii, while blue and white represent the situation involving intermolecular contacts longer and equal to the sum of van der Waals (vdW) radii, respectively (Figure 5a). Thus, according to these $d_{\text {norm }}$ values mapped onto the Hirshfeld surface, the difference between the sums of van der Waals (vdW) radii can be seen, clearly indicating the specific region able to be involved in intermolecular contacts. As can be seen on the Hirshfeld surfaces of the BT compound, the most intense red regions occur around the $\mathrm{C}=\mathrm{O}$ and $\mathrm{C}=\mathrm{S}$ groups, due to bifurcation of the $\mathrm{N} 2-\mathrm{H} 2 \cdots \mathrm{O} 1$ and $\mathrm{C} 8-$ $\mathrm{H} 8 \cdots \mathrm{S} 1$ hydrogen bonds, in which the $\mathrm{O}$ and $\mathrm{S}$ atoms act as an H-bond acceptor. Moreover, red regions are observed near the ortho $\mathrm{C}-\mathrm{H}$ of both aromatic groups, which act as

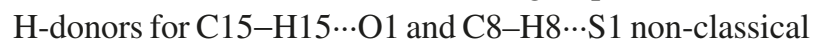
hydrogen bonds. The fingerprint plot shows that the $\mathrm{O} \cdots \mathrm{H}$, $\mathrm{S} \cdots \mathrm{H}, \mathrm{C} \cdots \mathrm{H}$, and $\mathrm{H} \cdots \mathrm{H}$ intermolecular contacts with relative contributions $13.5,11.9,24.8$ and $33.9 \%$, respectively, are very important interactions to stabilize the crystal assembly.

${ }^{1} \mathrm{H}$ and ${ }^{13} \mathrm{C}\left\{{ }^{1} \mathrm{H}\right\},{ }^{1} \mathrm{H}-{ }^{1} \mathrm{H}$ COSY, ${ }^{1} \mathrm{H}-{ }^{13} \mathrm{C} H S Q C, N M R$ analyses

The one (1D) and two-dimensional (2D) ${ }^{1} \mathrm{H}$ and ${ }^{13} \mathrm{CNMR}$ experiments were used to assign the $N$-[(phenylcarbonyl) carbamothioyl]benzamide compound. $1 \mathrm{D}^{1} \mathrm{H}$ and ${ }^{13} \mathrm{C} \mathrm{NMR}$, 2D HSQC and ${ }^{1} \mathrm{H}-{ }^{1} \mathrm{H}-\mathrm{COSY}$ in $\mathrm{CD}_{2} \mathrm{Cl}_{2}$ confirm the purity and the proposed structure of BT. It was determined the chemical shifts and all bound hydrogen positions related to each carbon atom, shown in Figures 6-7 and Figures S2 and S3 (Supplementary Information (SI) section).

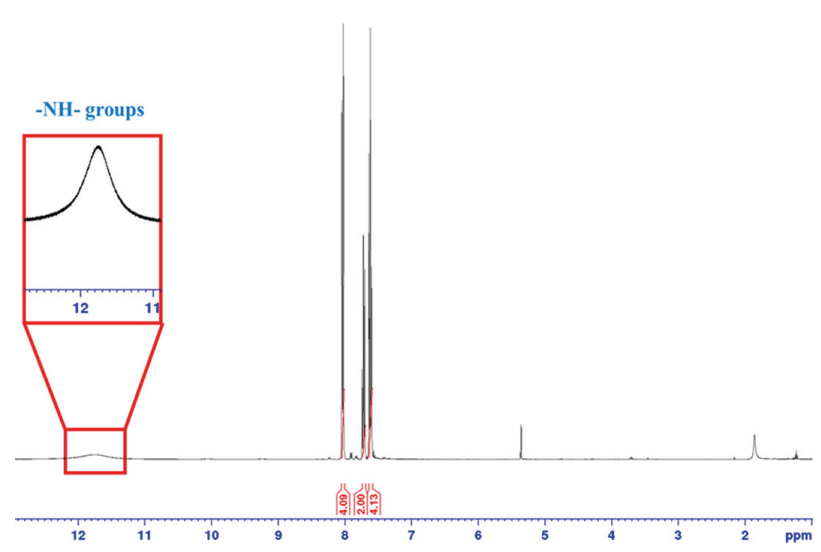

Figure 6. ${ }^{1} \mathrm{H}$ NMR spectrum $\left(400.21 \mathrm{MHz}, \mathrm{CD}_{2} \mathrm{Cl}_{2}\right)$ of $\mathrm{BT}$.

The BT ${ }^{1} \mathrm{H}$ NMR spectrum is dominated by the protons in the aromatic region (7.72-8.03), i.e., benzene ring protons. The signal at $7.72 \mathrm{ppm}$, whose integral is $2 \mathrm{H}$, is attributed to the hydrogens bound to $\mathrm{C}_{6}$ and $\mathrm{C}_{13}$ atoms (see Figure 3 for atoms numbering). The signal at $7.61 \mathrm{ppm}$, 


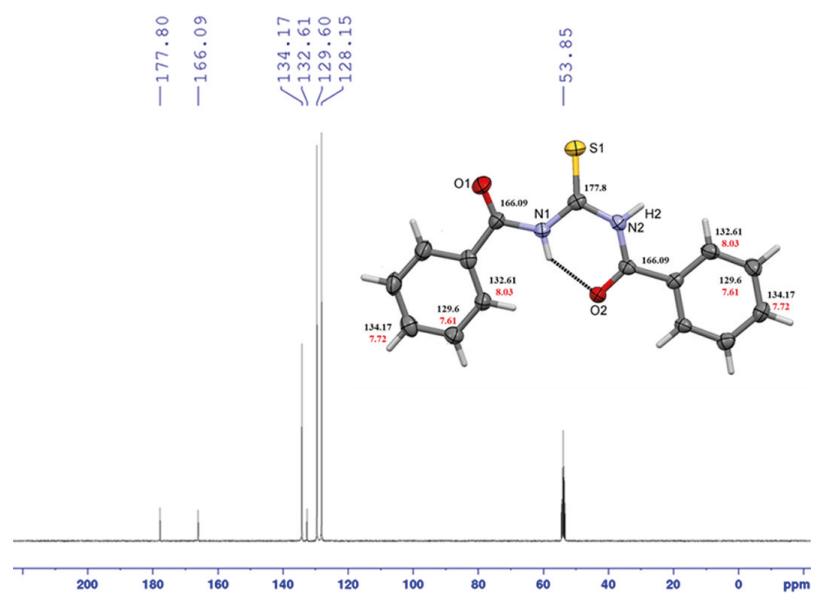

Figure 7. ${ }^{13} \mathrm{C} \mathrm{NMR}$ spectrum $\left(100 \mathrm{MHz}, \mathrm{CD}_{2} \mathrm{Cl}_{2}\right)$ and the structure of $\mathrm{BT}$ with chemical shifts of ${ }^{1} \mathrm{H}$ (red) and ${ }^{13} \mathrm{C}$ (black).

whose integral is $4 \mathrm{H}$, is attributed to the hydrogen bound to $\mathrm{C}_{5}\left(\mathrm{C}_{12}\right)$ and $\mathrm{C}_{7}\left(\mathrm{C}_{14}\right)$ atoms and the signal at $8.03 \mathrm{ppm}$ is attributed to the less shielded protons, which are near carboxyl groups bound at $\mathrm{C}_{4}\left(\mathrm{C}_{11}\right)$ and $\mathrm{C}_{8}\left(\mathrm{C}_{15}\right)$ atoms. At $11.75 \mathrm{ppm}$, there is an enlarged signal corresponding to the $\mathrm{H}$ atoms directly bound to nitrogen atoms.

In the ${ }^{13} \mathrm{C}$ NMR spectrum, carbon atoms $\mathrm{C}_{3}$ and $\mathrm{C}_{10}$ are assigned at $132.61 \mathrm{ppm}$, which is the region where aromatic carbon atoms do not bind any protons. The less shielded carbon atoms, $\mathrm{C}_{2}$ and $\mathrm{C}_{9}$ of carbonyls, were assigned at $166.09 \mathrm{ppm}$. At $177.8 \mathrm{ppm}$, the thiocarbonyl carbon $\mathrm{C}_{1}$ is assigned. The location of $\mathrm{C}_{1}$, between two electronegative nitrogen atoms and sulfur atom, increases the deshielding of this carbon.

\section{Mass spectrometry}

The BT compound $\left[\mathrm{C}_{15} \mathrm{H}_{12} \mathrm{~N}_{2} \mathrm{O}_{2} \mathrm{~S}\right]$ has a molecular weight equal to 284.33 a.u., and mass spectrometry experiments show two main signals (MALDI-TOF and MS/MS mass spectra, Figures S4, S5 and S6, SI section), one peak at $m / z 285.207$, which can be attributed to the molecular ion peak $\left[\mathrm{C}_{15} \mathrm{H}_{12} \mathrm{~N}_{2} \mathrm{O}_{2} \mathrm{~S}\right] \mathrm{H}^{+}$, and the most intense peak at $m / z 105.03$ attributed to the detection of the benzoyl group. Figure 8 shows the thiourea fragmentation pattern.

\section{UV-Vis spectroscopy}

The experimental and theoretical spectra of the BT compound are reported in Figure 9. The experimental spectrum was obtained in DMSO as a solvent (concentration of $4.4 \times 10^{-5} \mathrm{~mol} \mathrm{~L}^{-1}$ ), while the theoretical spectra were calculated using the functional CAM-B3LYP in the gas phase and in DMSO using the PCM. The maximum absorptions in the experimental spectrum occurred at

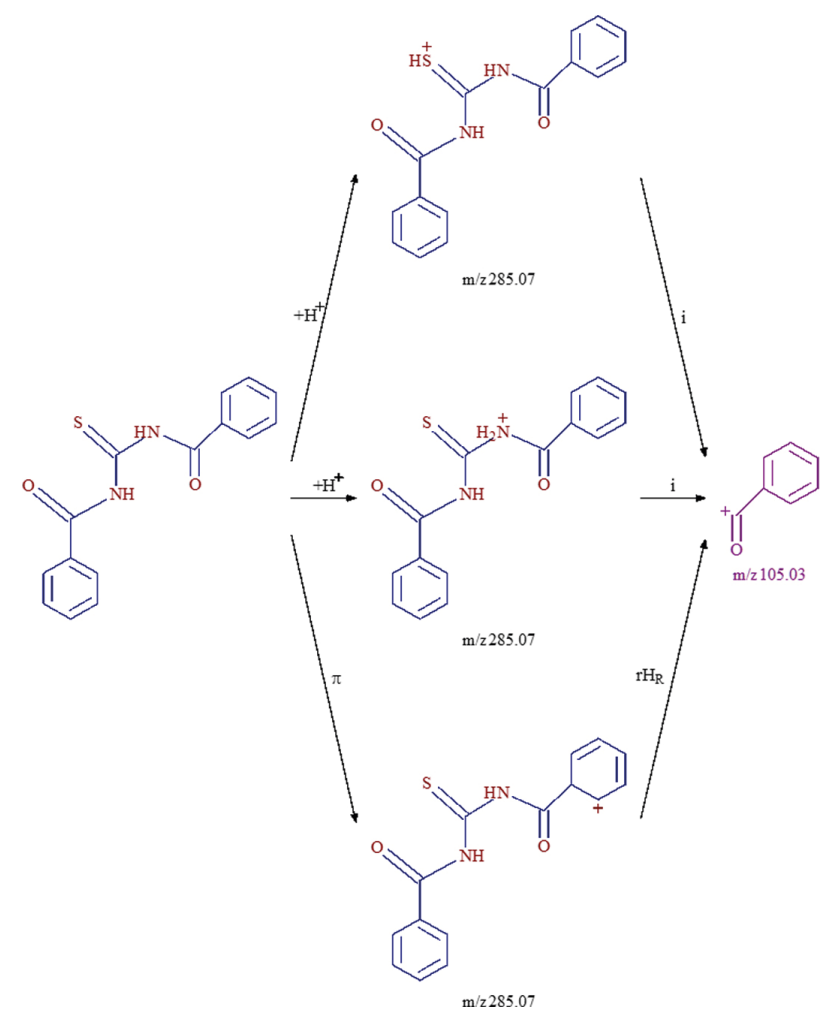

Figure 8. Assignment of the two main peaks obtained in the mass spectrum of the compound BT.

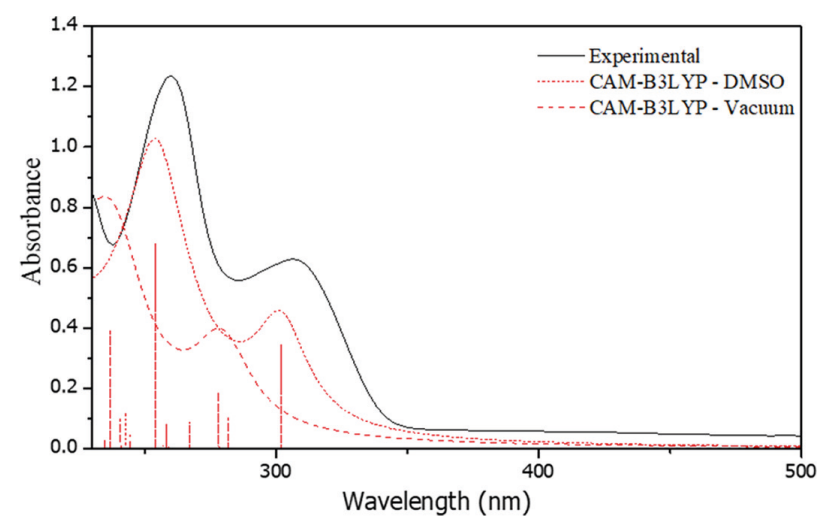

Figure 9. UV-Vis experimental spectrum of BT (black solid line) in DMSO, and theoretical (red dashed lines) at CAM-B3LYP/6$311++\mathrm{G}(2 \mathrm{~d}, 2 \mathrm{p}) / / \mathrm{B} 3 \mathrm{LYP} / 6-311++\mathrm{G}(2 \mathrm{~d}, 2 \mathrm{p})$ level.

$260 \mathrm{~nm}\left(v=19564.2 \mathrm{~cm}^{-1}\right)$ and $312 \mathrm{~nm}\left(v=9968.3 \mathrm{~cm}^{-1}\right)$, attributed to the transitions of type $\mathrm{n} \rightarrow \pi^{*}$ and $\pi \rightarrow \pi^{*}$, respectively.

The first transition is an $\mathrm{n} \rightarrow \pi^{*}$ transition, which tends to have lower molar absorptivity, since this transition is symmetry-forbidden in the $\mathrm{C}_{2}$ geometry. As the $\mathrm{C}_{2}$ symmetry is broken, it is expected that the transition gains in strength, but it is still weak. Thus, there is no significant special overlap between HOMO (highest occupied molecular orbital) and LUMO (lowest unoccupied molecular orbital), i.e., the transition from 
the $\pi$ non-bonding molecular orbital (HOMO), basically formed by $\mathrm{p}_{\mathrm{x}}$ sulfur atomic orbital, to the $\pi$ anti-bonding molecular orbital (LUMO), basically formed by $\mathrm{p}_{\mathrm{y}}$ carbon atomic orbitals, is expected to be very weak and thus does not appear in the experimental UV-Vis spectrum, as its intensity is under the detection limit. Furthermore, the fact that the solvent (acetone) is polar contributed to the decrease in absorptivity, as the lone pair of sulfur atom interacts strongly with the solvent. In the theoretical spectrum, this transition has excitation energy of $416.80 \mathrm{~nm}$ or $2.97 \mathrm{eV}$. However, this oscillator is very weak with an oscillator strength $\mathrm{f}$ ca. 0.0003 and, therefore, has little influence on the convolution curve.

The second transition is a more intense one at $301.80 \mathrm{~nm}$ or $4.11 \mathrm{eV}$. It corresponds to a $\pi \rightarrow \pi^{*}$ (LUMO) transition. It involves larger contributions of HOMO-1 and HOMO-6, both $\pi$ bonding orbitals. HOMO- 1 is formed mainly by the $p_{z}$ orbital of sulfur atom and HOMO- 6 by the $p_{z}$ orbitals of carbon atoms from the phenyl group.

The most intense transition is at $253.95 \mathrm{~nm}$ or $4.88 \mathrm{eV}$. It corresponds to a $\pi \rightarrow \pi^{*}$ (LUMO) transition. It involves contributions of HOMO-2 and HOMO- $1 \pi$-bonding orbitals. HOMO-2 has large contributions of $\mathrm{p}_{\mathrm{z}}$ orbitals of carbon atoms from the phenyl group.

\section{FTIR and Raman spectroscopy}

The experimental and theoretical infrared (IR) and Raman absorption spectra for BT are shown in Figures 10 and 11. DFT calculations showed no imaginary frequency, meaning that the optimized configurations (quasi-planar structures) were true minima on the respective potential energy surfaces. The vibrational infrared and Raman modes and the respective assignments using potential energy distribution (PED) implemented in the VEDA program ${ }^{41}$

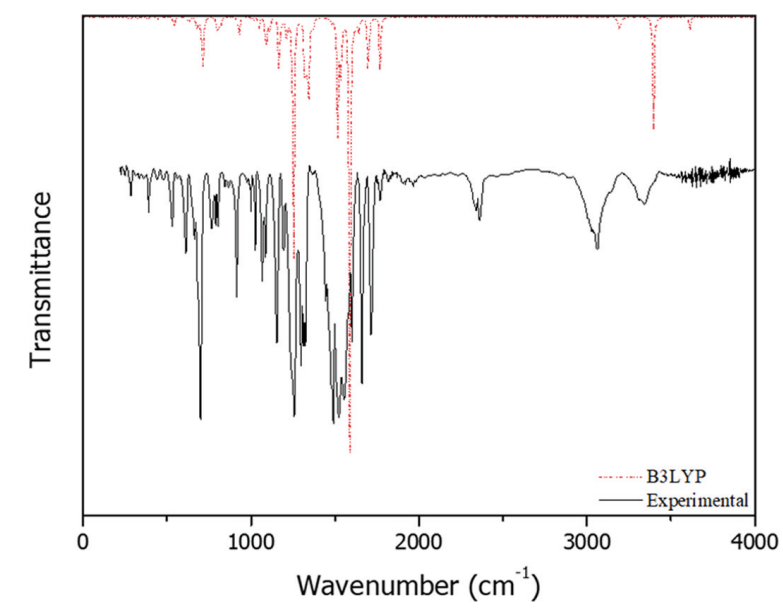

Figure 10. FTIR experimental spectrum (KBr) of BT (black solid line) and theoretical (red dashed line) at B3LYP/6-311++G(2d,2p) level.

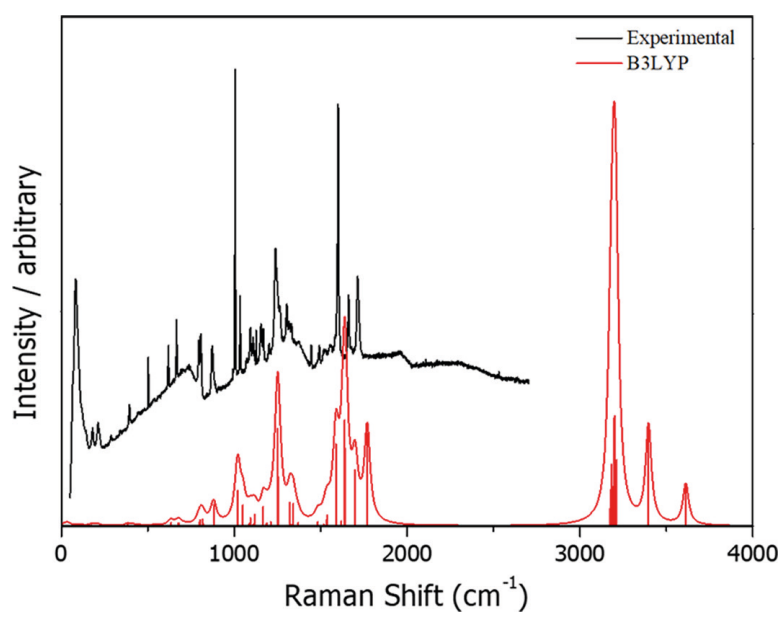

Figure 11. Raman experimental spectrum of BT (black upper line) and theoretical (red bottom line) at B3LYP/6-311++G(2d,2p) level.

are shown in Table S2 (SI section). There are 31 stretching, 30 bending deformation, and 29 torsion modes according to PDE analysis.

The infrared spectra showed strong absorbance in the range of $1200-1600 \mathrm{~cm}^{-1}$, which is mainly assigned to the carbon nitrogen modes. The five most intense IR frequencies are: $1588.61 \mathrm{~cm}^{-1}\left(\delta_{\mathrm{s}} \mathrm{HNC}\right), 1254.36 \mathrm{~cm}^{-1}$ $\left(v_{\text {as }} \mathrm{CC}+\mathrm{v}_{\mathrm{as}} \mathrm{NC}\right), 1341.57 \mathrm{~cm}^{-1}\left(\mathrm{v}_{\mathrm{as}} \mathrm{NC}+\mathrm{v}_{\mathrm{as}} \mathrm{CC}\right)$, $1517.50 \mathrm{~cm}^{-1}\left(\delta_{\mathrm{s}} \mathrm{HNC}+\delta_{\mathrm{s}} \mathrm{HCC}\right), 3396.13 \mathrm{~cm}^{-1}\left(\mathrm{v}_{\mathrm{s}} \mathrm{NH}\right)$. The five most intense Raman frequencies are: $3261.29 \mathrm{~cm}^{-1}$ $\left(v_{\mathrm{s}} \mathrm{CH}\right), 3260.18 \mathrm{~cm}^{-1}\left(\mathrm{v}_{\mathrm{s}} \mathrm{CH}\right), 1670.64 \mathrm{~cm}^{-1}\left(\mathrm{v}_{\mathrm{as}} \mathrm{CC}\right)$, $1274.2 \mathrm{~cm}^{-1}\left(v_{\mathrm{s}} \mathrm{CC}+\mathrm{v}_{\mathrm{as}} \mathrm{NC}+\rho \mathrm{HNC}\right), 3461.41 \mathrm{~cm}^{-1}$ $\left(v_{\mathrm{s}} \mathrm{NH}\right) . \mathrm{N}-\mathrm{H}$ stretching modes are decoupled due to the different chemical environment, i.e., the hydrogen bond formation. $\mathrm{H}_{1}-\mathrm{N}_{1}$ stretching (number 89 in Table S2, SI section) is red-shifted. The hydrogen bond $\mathrm{N}_{1}-\mathrm{H}_{1} \cdots \mathrm{O}_{2}$ weakens the $\mathrm{H}_{1}-\mathrm{N}_{1}$ bond, as some electronic density is involved in the hydrogen bonding. This fact is also seen at a lower frequency (lower force constant) when compared to $\mathrm{H}_{2}-\mathrm{N}_{2}$ stretching (number 90 in Table S2, SI section). A lower constant means a weaker bond and thus a more acidic hydrogen. The same features can be seen in the Raman spectrum. Experimental Raman spectrum shows two very intense peaks, one at $1619.14 \mathrm{~cm}^{-1}$ and the other at $1039.28 \mathrm{~cm}^{-1}$, which correspond to $\delta_{\mathrm{s}} \mathrm{HNC}$ (mode 72 ) and $\delta_{\mathrm{s}} \mathrm{CCC}$ (mode 47 ), respectively. In the theoretical IR spectrum of the compound with dihedral angle $\mathrm{H}_{1}-\mathrm{N}_{1}-\mathrm{N}_{2}-\mathrm{H}_{2}$ equal to $55^{\circ}$ (minimum point, see Figure 10), the stretchings of $\mathrm{N}-\mathrm{H}$ are coupled and two peaks $\left(v_{\mathrm{s}}\right.$ and $\left.v_{\mathrm{as}}\right)$ with almost the same intensity (oscillator strength) appear around $3600 \mathrm{~cm}^{-1}$. In this structure, there is no intramolecular hydrogen bond. Thiol groups are characterized at 1094.54 and $816.05 \mathrm{~cm}^{-1}$, which are assigned to the $\mathrm{C}-\mathrm{S}$ stretching vibration. The experimental band around $2400 \mathrm{~cm}^{-1}$ (IR spectrum) is related to air $\mathrm{CO}_{2}$ 
absorption and therefore does not appear in the theoretical spectrum.

\section{Computational analysis}

All the geometry optimizations converged to a quasi-planar structure, with an $\mathrm{N}_{1}-\mathrm{H}_{1} \cdots \mathrm{O}_{2}$ bond length around $1.8 \AA$ and angle bond about $140^{\circ}$, which indicates the presence of the intermolecular hydrogen bond. This bond persists even in calculations with implicit solvents. The optimized structure is similar to that in Figure 3 and can be seen in the Supplementary Information (Figure S1). The theoretical structural parameters are quite similar to those obtained by X-ray crystallography, as shown in Table 2. All principal structural properties calculated have a relative error below $2 \%$. Rings are out-of-plane by about $30^{\circ}$ in the gas phase and a little more, by $45^{\circ}$, in the solvent environment. The crystallographic structure value is $28^{\circ}$.

The HOMO and LUMO energies ( $\mathrm{E}_{\text {номо }}$ and $\left.\mathrm{E}_{\mathrm{LUMO}}\right)$ and HOMO-LUMO gap (HLG) for the BT molecule in the gas phase and also in acetone (implicit solvent model) are presented in Table 3 for three different DFT functionals. It should be mentioned that the B3LYP functional presented better computational cost vs. accuracy.

Solvent medium stabilizes total molecular energy and molecular orbitals energies. Stabilization is greater for the HOMO, which has a large contribution of $\mathrm{p}_{\mathrm{x}}$ orbital of sulfur atom (i.e., the lone-pair orbital), than for the LUMO, which has mainly contributions of $\mathrm{p}_{\mathrm{z}}$ orbitals of carbon atoms. Such behavior is expected and might be related to the low intensity of $\mathrm{n} \rightarrow \pi^{*}$ transition (HOMO-LUMO transition), which is suppressed in the experimental UV-Vis spectrum (see Figure 9), very likely by the detection limit of the spectroscope. Figure S7 (SI section) shows HOMO and LUMO representation and gap energy of the optimized structure at the B3LYP/6-311++G(2d,2p) level.
To investigate the configuration space and the contribution of the intermolecular hydrogen bond to the structure configuration, it was performed a scan of the dihedral angle $\mathrm{H}_{1}-\mathrm{N}_{1} \cdots \mathrm{N}_{2}-\mathrm{H}_{2}$ in the solvent environment. This study was performed to verify the lower energy conformer when the selected dihedral angle that generates the cisoide and transoid configurations of the $\mathrm{N}-\mathrm{H}$ groups in relation to $\mathrm{C}=\mathrm{S}$ varied, and the profile obtained is quite similar in both acetone and DMSO. The energy profile is quite similar for both solvents: acetone and DMSO.

From the scan in Figure 12, it can be observed that the lowest energy configuration is the one with the hydrogen bond, i.e., the hydrogen atoms of amide groups are oriented differently; while one is syn-periplanar in relation to the thiol group, the other is anti-periplanar. The latter is the one that forms the hydrogen bond.

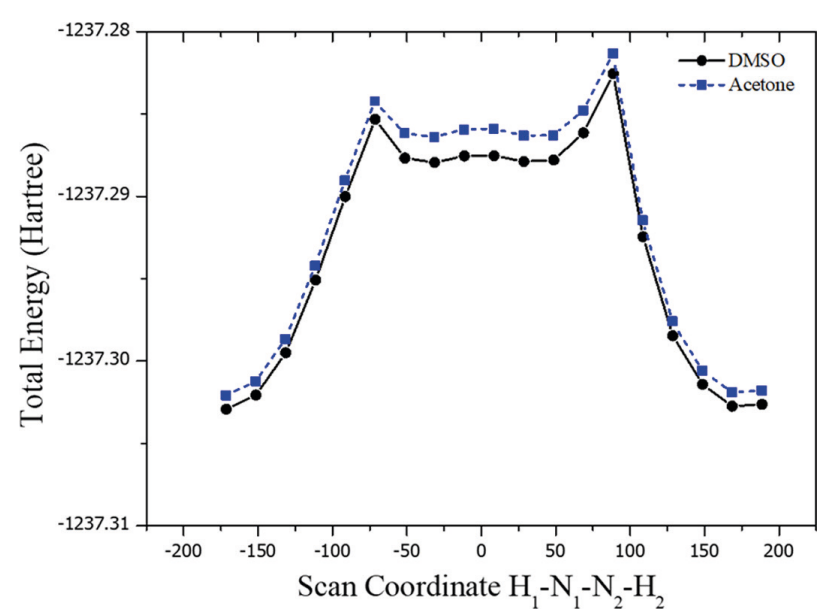

Figure 12. Dihedral $\mathrm{H}_{1}-\mathrm{N}_{1}-\mathrm{N}_{2}-\mathrm{H}_{1}$ relaxed scan in acetone and DMSO at B3LYP/6-311++G(2d,2p) level.

According to Figure 3, the most stable configuration is achieved when dihedral angle $\mathrm{H}_{1}-\mathrm{N}_{1}-\mathrm{N}_{2}-\mathrm{H}_{2}$ is about $177^{\circ}$ and benzyl rings have angle of $49^{\circ}$ between each

Table 3. Energies (HOMO, LUMO and HLG), in vacuum and acetone, for the BT compound, calculated by DFT functional, B3LYP, M062X and B3PW91 programs

\begin{tabular}{lccccc}
\hline DFT functional & Total energy / hartree & Dipole moment / debye & $\mathrm{E}_{\text {номо }} / \mathrm{eV}$ & $\mathrm{E}_{\text {LUмо }} / \mathrm{eV}$ & HLG / eV \\
\hline B3LYP & -1237.29 & 6.23 & Vacuum & & \\
M062X & -1236.92 & 6.10 & -6.06 & -2.56 & 3.50 \\
B3PW91 & -1236.90 & 6.24 & -6.10 & -1.56 & 3.99 \\
\hline & & \multicolumn{2}{c}{ Solvent (acetone) } & & 3.53 \\
\hline B3LYP & -1237.30 & 8.91 & -6.45 & -2.68 & 3.77 \\
M062X & -1236.93 & 8.62 & -7.94 & -1.73 & 6.21 \\
B3PW91 & -1237.30 & 8.86 & -6.46 & -2.69 & 3.77 \\
\hline
\end{tabular}

HOMO: highest occupied molecular orbital; LUMO: lowest unoccupied molecular orbital; HLG: HOMO LUMO gap; DFT: density functional theory. 
other. The most unstable configuration has dihedral angle $\mathrm{H}_{1}-\mathrm{N}_{1}-\mathrm{N}_{2}-\mathrm{H}_{2}$ about $90^{\circ}$ and the relative position of benzyl rings about $120^{\circ}$.

The scans show two local minima: one with dihedral angle $\mathrm{H}_{1}-\mathrm{N}_{1}-\mathrm{N}_{2}-\mathrm{H}_{2}$ equal to $-40^{\circ}$ and the symmetric counterpart, $40^{\circ}$. The relative angle between the benzyl groups in these structures is around $85^{\circ}$. Between these configurations, there is a maximum point where the same dihedral angle is almost $0^{\circ}$, which means that hydrogen atoms from amide groups are aligned (anti-periplanar with thiol group) and the benzyl groups are by $112^{\circ}$ out-of-plane. Therefore, the sulfur and oxygen atoms are also aligned (syn-periplanar). Although those configurations are energy minima, the difference between the global minimum is still large, about $0.42 \mathrm{eV}$. This energy difference is by the order of magnitude larger than the thermal energy $\mathrm{k}_{\mathrm{B}} \mathrm{T}$, which for $300 \mathrm{~K}$ equals to $0.04 \mathrm{eV}$. Of course, this comparison is rough, but it at least gives an idea if the thermal energy would be enough to overcome the rotation barrier at room temperature, for example. It can be concluded that most of the molecules assume the minimum configuration even in the solvent phase, which means that the intermolecular hydrogen bond remains when the molecules are solvated. Overall, it can be said that two geometric parameters are relevant to the configuration energy, i.e., stabilization, which is the relative position of phenyl groups, and the formation of the intermolecular hydrogen bond $\mathrm{N}_{1}-\mathrm{H}_{1} \cdots \mathrm{O}_{2}$. The latter is related to the relative position of amide hydrogens.

\section{Molecular electrostatic potential (MEP) surface}

The molecular electrostatic potential (MEP) surface was plotted on the optimized structure of BT in the gas phase, and is a powerful tool for analyzing and recognizing the donor and acceptor regions of electron density. ${ }^{42,43}$ Figure 13 shows the computationally obtained MEP surface map with the point charges fitting to the electrostatic potential V(r) calculated for the BT, and shows the negative regions (red) and the positive regions (blue).

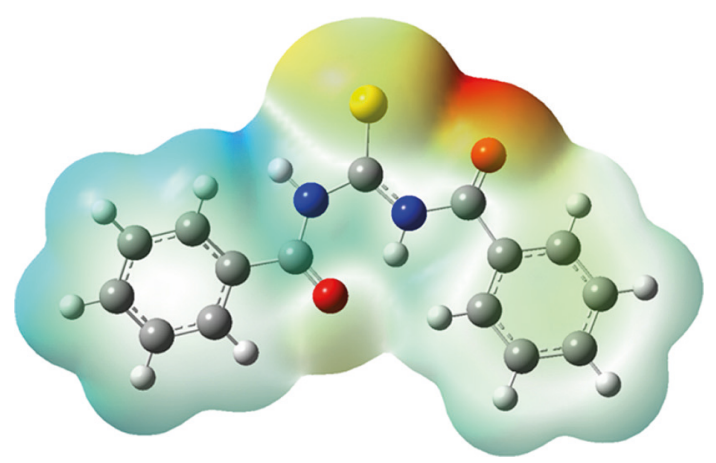

Figure 13. The computationally obtained MEP surface maps for the BT.
The region with the highest negative charge density is centered on atom $\mathrm{O} 1$ as atom $\mathrm{O} 2$ has hydrogen bonding with $\mathrm{H} 1$, reducing the charge density on the $\mathrm{O} 2$ atom, which is in agreement with the data obtained from the Hirshfeld surface analysis.

In order to verify the electronic densities distribution by the NBO analysis, in the Tables S5 and S6 (SI section) are shown the NBO charges of the atoms, considering both structural forms cis and trans configurations of the BT molecule (Figure S8, SI section), and a complete analysis of the data is presented in the Supplementary Information. The data indicate that the sulfur atom displays the largest difference between these forms, which suggest that the electronic charge are more localized in trans-BT than in cis-BT form, which agrees with the experimental data, as can be clearly seen by the topological analysis of the structure of the BT molecule (Figures S9 and S10, SI section). Such difference might be understood by the breakdown of resonance structure of the $\mathrm{S}-\mathrm{C}-\mathrm{N}-\mathrm{C}-\mathrm{O}$ system.

The strongest stabilization of the trans-BT molecule is associated with the lone pair orbital of oxygen and nitrogen atoms. In all cases, the $\pi *$ antibonding orbitals of these atoms participate as acceptors, while the lone pairs of them act as donors in the intermolecular interaction, $\mathrm{n}_{\text {atom }} \rightarrow \pi^{*}$ orbitals. As result, the occupation number of these antibonding orbitals is fairly high. The NBO analysis reveals that there is a strong intramolecular interaction of charge transfer from oxygen lone pairs to the $\mathrm{N} 1-\mathrm{H} 1$, in an antibonding orbital $\left(\mathrm{n}_{\mathrm{O} 2} \rightarrow \sigma^{*}{ }_{\mathrm{N} 1-\mathrm{H} 1}\right)$. As a consequence, the occupation number of these orbitals is quite lower $\left(\mathrm{n}_{\mathrm{O} 2 \text { orbital }}\right)$ and higher $\left(\sigma^{*}{ }_{\mathrm{N} 1-\mathrm{H} 1}\right)$ than those of the cis configuration, and a significant decrease of this intramolecular interaction was observed, which is in agreement with the experimental observation, where only the trans-BT structure was obtained.

\section{Conclusions}

The thiourea derivative, $N$-[(phenylcarbonyl) carbamothioyl]benzamide, was synthesized and fully characterized. A new synthetic route for the synthesis of the symmetric thiourea derivatives, with high purity and high yield, was presented. This route can be easily used to produce other thioureas by simply changing the reactant, i.e., the functional group of interest. The BT compound crystallized in the centrosymmetric space group $\mathrm{P} 2_{1} 2_{1} 2_{1}$ and the DFT analysis showed good agreement with the X-ray results. Moreover, the vibrational FTIR and Raman spectra of the compound were recorded and assigned using experimental and computed vibrational wavenumbers. 
Good agreement for both vibrational and electronic spectra was obtained.

An important result is related to the presence of the intramolecular hydrogen bond, which is a quite strong interaction and might play a noticeable role even in the liquid phase. Its relative strength was estimated by geometry optimizations for several structures (relaxed scan) where this hydrogen bond length was constantly varied. In conclusion, the rotation barrier is too high to be overcome by simple thermal energy.

In summary, a new methodology for obtaining symmetric thioureas quickly and easily was proposed, with high purity and high yield, and also the data presented in this paper can help to better understand this class of thioureas. We hope that the method described here will be used by others, making the synthesis of this important class of compounds more efficient, cheaper, and generating less waste.

\section{Supplementary Information}

Crystallographic data for the structure (BT) reported in this paper have been deposited with the Cambridge Crystallographic Data Center, CCDC No. 1582900. Copies of the data can be obtained, free of charge, on application to CCDC, 12 Union Road, Cambridge CB2 1EZ, UK (fax: +44 1223 336033; e-mail: deposit@ccdc.cam.ac.uk or http://www.ccdc.cam.ac.uk).

The data of ${ }^{1} \mathrm{H}$ and ${ }^{13} \mathrm{C}$ NMR, MS, representation of HOMO and LUMO and vibrational assignments for compound BT are available free of charge at http://jbcs. sbq.org.br as PDF file.

\section{Acknowledgments}

The authors are grateful for the support provided by CAPES and CNPq (A. E. Kuznetsov). R. S. Correa would also like to thank CNPq for the financial support (project 403588/2016-2).

\section{References}

1. Andreae, S.; Schimtz, E.; J. Prakt. Chem. 1987, 329, 1008.

2. Gardner, J. O.; J. Org. Chem. 1980, 45, 3909.

3. Singh, G.; Saroa, A.; Rani, S.; Promila; Girdhar, S.; Sahoo, S.; Choquesillo-Lazarte, D.; Polyhedron 2016, 112, 51.

4. Madabhushi, S.; Mallu, K. K.; Vangipuram, V. S.; Kurva, S.; Poornachandra, Y.; Kumar, C. G.; Bioorg. Med. Chem. Lett. 2014, 24, 4822.

5. Saeed, A.; Ashraf, S.; White, J. M.; Soria, D. B.; Franca, C. A.; Erben, M. F.; Spectrochim. Acta, Part A 2015, 150, 409.
6. Serdyuk, O. V.; Heckel, C. M.; Tsogoeva, S. B.; Org. Biomol. Chem. 2013, 11, 7051.

7. Lin, T. L.; Lien, H. L.; J. Mol. Struct. 2013, 14, 9834.

8. Mushtaque, M.; Jahan, M.; Ali, M.; Khan, M. S.; Khan, M. S.; Preeti, S.; Kesarwani, A.; J. Mol. Struct. 2016, 1122, 164.

9. Schoultz, X.; Gerber, T. I. A.; Hosten, E. C.; Polyhedron 2016, $113,55$.

10. Stefanska, J.; Szulczyk, D.; Koziol, A. E.; Miroslaw, B.; Kedzierska, E.; Fidecka, S.; Busonera, B.; Sanna, G.; Giliberti, G.; La Colla, P.; Struga, M.; Eur. J. Med. Chem. 2012, 55, 205.

11. Venkatachalam, T. K.; Mao, C.; Uckun, F. M.; Bioorg. Med. Chem. 2004, 12, 4275.

12. Karakus, S.; Kucukguzel, S. G.; Kucukguzel, I.; De Clercq, E.; Pannecouque, C.; Andrei, G.; Snoeck, R.; Sahin, F.; Bayrak, O. F.; Eur. J. Med. Chem. 2009, 44, 3591.

13. Yonova, P. A.; Stoilkova, G. M.; J. Plant Growth Regul. 1997, $23,280$.

14. Sheldrick, G. M.; Acta Crystallogr., Sect. A: Found. Adv. 2008, 64, 112.

15. Sheldrick, G. M.; SHELXL97, Program for Crystal Structure Refinement; University of Göttingen, Germany, 1997.

16. Enraf-Nonius; COLLECT; Nonius BV, Delft, The Netherlands, 1997.

17. Frisch, M. J.; Trucks, G. W.; Schlegel, H. B.; Scuseria, G. E.; Robb, M. A.; Cheeseman, J. R.; Scalmani, G.; Barone, V.; Mennucci, B.; Petersson, G. A.; Nakatsuji, H.; Caricato, M.; Li, X.; Hratchian, H. P.; Izmaylov, A. F.; Bloino, J.; Zheng, G.; Sonnenberg, J. L.; Hada, M.; Ehara, M.; Toyota, K.; Fukuda, R.; Hasegawa, J.; Ishida, M.; Nakajima, T.; Honda, Y.; Kitao, O.; Nakai, H.; Vreven, T.; Montgomery Jr., J. A.; Peralta, J. E.; Ogliaro, F.; Bearpark, M.; Heyd, J. J.; Brothers, E.; Kudin, K. N.; Staroverov, V. N.; Kobayashi, R.; Normand, J.; Raghavachari, K.; Rendell, A.; Burant, J. C.; Iyengar, S. S.; Tomasi, J.; Cossi, M.; Rega, N.; Millam, J. M.; Klene, M.; Knox, J. E.; Cross, J. B.; Bakken, V.; Adamo, C.; Jaramillo, J.; Gomperts, R.; Stratmann, R. E.; Yazyev, O.; Austin, A. J.; Cammi, R.; Pomelli, C.; Ochterski, J. W.; Martin, R. L.; Morokuma, K.; Zakrzewski, V. G.; Voth, G. A.; Salvador, P.; Dannenberg, J. J.; Dapprich, S.; Daniels, A. D.; Farkas, Ö.; Foresman, J. B.; Ortiz, J. V.; Cioslowski, J.; Fox, D. J.; Gaussian 09, Revision A.02; Gaussian, Inc., Wallingford, CT, 2009.

18. Mehdi, A.; Adane, L.; Patel, D. S.; Bharatam, P. V.; J. Comput. Chem. 2009, 31, 1259.

19. McLean, A. D.; Chandler, G. S.; J. Chem. Phys. 1980, 72, 5639.

20. Frisch, M. J.; Pople, J. A.; Binkley, J. S.; J. Chem. Phys. 1984, $80,3265$.

21. Becke, A. D.; J. Chem. Phys. 1993, 98, 5648.

22. Lee, C.; Yang, W.; Parr, R. G.; Phys. Rev. B: Condens. Matter Mater. Phys. 1988, 37, 785.

23. Parr, R. G.; Yang, W.; Density-Functional Theory of Atoms and Molecules; Oxford University Press: New York, 1989. 
24. Zhao, Y.; Truhlar, D. G.; Theor. Chem. Acc. 2007, 120, 215.

25. Yanai, T.; Tew, D. P.; Handy, N. C.; Chem. Phys. Lett. 2004, 393, 51.

26. Barone, V.; Cossi, M.; Tomasi, J.; J. Chem. Phys. 1997, 107, 3210.

27. Reed, A. E.; Curtiss, L. A.; Weinhold, F.; Chem. Rev. (Washington, DC, U. S.) 1988, 88, 899.

28. Schaftenaar, G.; Noordik, J. H.; J. Comput.-Aided Mol. Des. 2000, 14, 123.

29. Glendening, E. D.; Reed, A. E.; Carpenter, J. E.; Weinhold, F.; NBO, version 3.1; University of Wisconsin, Madison, WI, 2009.

30. Bader, R. W. F.; Chem. Rev. (Washington, DC, U. S.) 1991, 91 , 893.

31. Becke, A. D.; Edgecombe, K. E.; J. Chem. Phys. 1990, 92, 5397.

32. Tian, C. F. W.; J. Comput. Chem. 2012, 33, 580.

33. Ballini, R.; Bosica, G.; Fiorini, D.; Maggi, R.; Righi, P.; Sartori, G.; Sartorio, R.; Tetrahedron Lett. 2002, 42, 8445.

34. Qiao, L.; Huang, J.; Hu, W.; Zhang, Y.; Guo, J.; Cao, W.; Miao, K.; Qin, B.; Song, J.; J. Mol. Struct. 2017, 1139, 149.

35. Rauf, M. K.; Zaib, S.; Talib, A.; Ebihara, M.; Badshah, A.; Bolte, M.; Iqbal, J.; Bioorg. Med. Chem. 2016, 24, 4452.
36. Saeed, A.; Parvez, M.; Cent. Eur. J. Chem. 2005, 3, 780.

37. Li, G.; Zhao, M. M.; Wang, L.; Yang, Y. H.; Zhang, Y. J.; Dong, X. Y.; Asian J. Chem. 2013, 25, 4334.

38. Kaminsky, W.; Goldberg, K. I.; West, D. X.; J. Mol. Struct. 2002, 605, 9 .

39. Bruno, I. J.; Cole, J. C.; Kessler, M.; Luo, J.; Motherwell, W. D. S.; Purkis, L. H.; Smith, B. R.; Taylor, R.; J. Chem. Inf. Comput. Sci. 2004, 44, 2133.

40. Hung, W. W.; Kassim, M. B.; Acta Crystallogr., Sect. E: Crystallogr. Commun. 2010, 66, 3182.

41. Jamróz, M. H.; Spectrochim. Acta, Part A 2013, 114, 220.

42. Afzali, R.; Vakili, M.; Boluri, E.; Tayyari, S. F.; Nekoei, A. R.; Hakimi-Tabar, M.; Darugar, V.; Spectrochim. Acta, Part A 2017, $190,15$.

43. Leela, J. S.; Hemamalini, R.; Muthu, S.; Al-Saadi, A. A.; Spectrochim. Acta, Part A 2015, 146, 177.

Submitted: February 20, 2018 Published online: July 2, 2018 